\title{
Alzheimer's Disease: A Neurodegenerative Menace of Elderly
}

\author{
Wahied Khawar Balwan ${ }^{1 *}$ and Neelam Saba ${ }^{2}$
}

${ }^{1}$ Assistant Professor, Department of Zoology, Govt. Postgraduate College Bhaderwah, Jammu \& Kashmir, India
${ }^{2}$ Assistant Professor, Department of Zoology, Govt. Degree College Doda, Jammu \& Kashmir, India

DOI: $10.36347 /$ sajb.2021.v09i05.001

| Received: 27.03.2021 | Accepted: 15.05.2021 | Published: 20.05.2021

*Corresponding author: Wahied Khawar Balwan

Abstract

Alzheimer's Disease is the most common cause of Dementia. This is an incurable, neurodegenerative and terminal disease. Despite mortality due to communicable diseases, poverty, and human conflicts, dementia incidence is destined to increase in the developing world in tandem with the ageing population. Current data from developing countries suggest that age adjusted dementia prevalence estimates in 65 year old are high (>or=5\%) in certain Asian and Latin American countries, but consistently low (1-3\%) in India and sub-Saharan Africa; Alzheimer's disease accounts for $60 \%$ whereas vascular dementia accounts for approximately $30 \%$ of the prevalence. Early-onset familial forms of dementia with single-gene defects occur in Latin America, Asia, and Africa. Illiteracy remains a risk factor for dementia. This review discusses the etiology, pathology, diagnosis \& treatment and scenario in India.

Keywords: Alzheimer's Disease, Dementia, Mortality, Neurodegenerative, Communicable, Ageing.

Copyright $\odot 2021$ The Author(s): This is an open-access article distributed under the terms of the Creative Commons Attribution 4.0 International License (CC BY-NC 4.0) which permits unrestricted use, distribution, and reproduction in any medium for non-commercial use provided the original author and source are credited.

\section{INTRODUCTION}

Alzheimer's disease (AD) and other forms of dementia are a growing public health problem among the elderly in developing countries, whose aging population is increasing rapidly. It is estimated that by the year 2020 , approximately $70 \%$ of the world's population aged 60 and above will be living in developing countries, with $14.2 \%$ in India (World Health Organisation, 1998). Dementia is a clinical manifestation in which decline in mental abilities and memory (cognitive functions) takes place in patients. The affected individual is not able to carry out his day-to-day activities. Older people with dementia are present worldwide. WHO predicts that around $71 \%$ of $81.1 \mathrm{~m}$ dementia cases will be in the developing world by 2040 ! There are no preventive or curative measures for most dementia cases. The most common cause of dementia is Alzheimer's disease or $\mathrm{AD}$ (around $60 \%$ cases). It is a progressive neurodegenerative disorder. The cases are confirmed by US National Institute of Neurological and Communicative Disorders and Stroke and the Alzheimer's disease and Related Disorders Association Criteria (NINCDS-ADRDA). Ageing is the primary risk factor for most neurodegenerative diseases, including Alzheimer disease (AD) and Parkinson disease (PD). One in ten individuals aged $\geq 65$ years has Alzheimer's disease and its prevalence continues to increase with increasing age. Few or no effective treatments are available for ageing-related neurodegenerative diseases, which tend to progress in an irreversible manner and are associated with large socioeconomic and personal costs (Hou et al., 2019). Alzheimer's disease usually begins with memory decline and later affects other cognitive abilities. Two different kinds of protein deposits in the patient's brain are involved in the disease namely Amyloid beta plaques and tau neurofibrillary tangles. The emergence of tau neurofibrillary tangles reflects disease progression: they first manifest in the brain's memory centers and then appear in other areas in the course of the disease. Tau proteins or tau aggregates probably migrate along nerve fibers and thereby contribute to the spreading of the disease throughout the brain (Susanne et al., 2019). The reported incidence rates for Alzheimer's disease has been lower in Asian countries than in the industrialized world (Chandra et al., 2001; Chen et al., 2011; Liu et al., 1998; Yoshitake et al., 1995). Although dementia prevalence studies are available from Asian countries including India (Chiu et al., 1998; DeSilva et al., 2003; Jitapunkul et al., 2001) there is a dearth of incidence, (Chandra et al., 2001; Chen et al., 2011; Liu et al., 1998; Yoshitake et al., 1995) data, particularly from prospective long-term studies.

\section{ETIOLOGY}

Alzheimer's Disease (AD) has a multi-factorial etiology. Various factors may increase the risk of dementia, viz. diet and lifestyle, mid-life history of disorders like hypertension, type 2 diabetes etc. and 
genetic predisposition (Kalaria et al., 2008). The behavioural and psychological symptoms are apathy, depression, sleep alterations, anxiety etc. In India, patients suffering from Alzheimer's disease have delusions, hallucinations, anxieties, phobias and caregiver distress. These are similar to those reported from developed countries. Early life exposure to deleterious conditions like poverty, infectious diseases, malnutrition, and pre-natal stress may influence ageing process. Early life negative events and physical attributes including brain development, body growth, socioeconomic conditions, head injury contributes as risk factors of Alzheimer's disease. Intellectually stimulating and socially engaging physical activities lowers the risk of Alzheimer's disease. Also diet rich in fruits, vegetables and fibres significantly reduce development of Alzheimer's disease.

\section{PATHOLOGY}

This incurable, degenerative and terminal disease was first described by German physicist, Alois Alzheimer in 1906 and was named after him. Both amyloid plaques and neurofibrillary tangles are visible in brains of Alzheimer's disease patients on autopsy. Alzheimer's disease has been identified as a protein mis-folding disease, caused by accumulation of abnormally folded 'A $\beta$ ' (amyloid $\beta$ ) protein and 'tau' proteins in the brain. Majority of AD cases are sporadic. A few of the familial forms follow autosomal dominant inheritance, which usually have an onset before $65 \mathrm{yr}$. Most of the inherited AD is attributed to mutations in one of the three genes: Amyloid Precurssor Protein (APP), Presenilin 1 (PS 1) and Presenilin 2 (PS2). Amyloid plaques are formed between nerve cells in the brain. A $\beta$ is formed after sequential cleavage of APP, a transmembrane glycoprotein of unknown function. Beta amyloid form clumps, that deposit outside neurons. APP can be cleaved by $\alpha, \beta$ and $\gamma$ secretase to from $\mathrm{A} \beta$ proteins of various lengths. A number of isoforms are generated varying in length viz. $A \beta-40$ and $A \beta-42$. Shorter forms e.g. $A \beta-40$ is more common and is produced by cleavage in trans-golgi network. A $\beta-42$, produced in endoplasmic reticulum is more fibrillogenic and is associated with plaques. Mutations in PS1 and PS2 alter the $\gamma$ secretase activity, such that $A \beta-42$ is produced. Beta amyloid peptide activates the surrounding microglia and astrocytes producing inflammatory mediators e.g. components of complement pathway, acute phase proteins, interleukin-6 etc. This may help in the formation of A $\beta$ (Capurso et al., 2004).

The other protein implicated in Alzheimer's disease, tau protein, forms prion like misfolded oligomers. Neurofibrillary tangles are insoluble twisted fibres found inside the neurones. The tangles primarily consist of tau, which forms part of microtubule, which helps transporting nutrients and other important substances from one part of neurons to the other. In Alzheimer's disease, tau protein is abnormal and microtubule structure collapse. Nonetheless most of
Alzheimer's disease cases do not exhibit autosomal dominant inheritance and are sporadic, genetic differences may act as risk factors. One of the risk factors is $\varepsilon 4$ allele of apolipoprotein E. This allele has been widely studied and is a well-established risk factor for Alzheimer's disease. Many studies have been conducted to find an association of interleukin6-174G/C polymorphism and Alzheimer's disease with varying results (Mansoori et al., 2010). There are other genes which may act as risk factors or have protective effects on Alzheimer's disease.

\section{Diagnosis and treatment}

AD is diagnosed clinically from patient history, clinical observations, and presence of characteristic neurological and psychological features and absence of alternative conditions. Advanced medical imaging with computed tomography (CT) or magnetic resonance imaging (MRI) and Single Photon Emission Computed Tomography (SPECT) or Position Emission Tomography (PET) can be used to help exclude other cerebral pathology. Currently used treatments have symptomatic benefits. Developing countries have traditional herbal medicinal practices that are good anti-dementia therapies. Several species of medicinal plants e.g. blueberry, cannabis, clubmoss, curcumin, garlic, ginseng, pomegranate etc. have activities relevant to dementia. Modern treatments of Alzheimer's disease are pharmaceutical, psychosocial and caregiving. Mementine (NMDA receptor antagonist) is the drug of choice. Acetylcholine esterase inhibitors are also used. Antipsychotic drugs are also used for reducing aggression and psychosis. Psychosocial therapies include behavioural, emotional, cognitive and stimulatory. Since Alzheimer's disease has no cure, caregiving must be carefully managed over the course of the disease. Clinical research is focused on treating the pathology of the disease. Immunotherapy and vaccination for the amyloid protein is one of the treatment modalities under investigation.

\section{Scenario in India}

In India, more than $4 \mathrm{~m}$ people are estimated to be suffering from Alzheimer's disease and other forms of dementia, giving the country the third highest case-load in the world, after china and the US. Alzheimer's disease in India is a hidden problem. Only a fraction of patients are diagnosed and treated. According to India Ageing Report, 2017, the elderly population, which is growing at a fast rate of $3 \%$, may increase the Alzheimer's disease cases. According to a study, social stigma surrounding Alzheimer's disease and dementia is impeding early diagnosis, care and research. Alzheimer's disease modifies survival and increases the risk of death. Understanding the burden and cost of Alzheimer's disease is crucial for future healthcare and socioeconomic policy. Teaching of coping strategies to the caregivers has improved their psychological health. National Policies to increase awareness, specialized training for health professionals, authorities, research 
and a proper counseling of caregivers etc. may help the growing number of Alzheimer's disease and other dementia patients in the long run. In a study carried out by Mathuranath et al., 2012, among the 1066 eligible participants who were cognitively normal at baseline, 104 developed dementia (98 with AD) over a follow-up period of 8.1 years. The incidence rates per 1000 person-years for $\mathrm{AD}$ was 11.67 (95\% CI: 10.9-12.4) for those aged $\geq 55$ years and higher for those aged $\geq 65$ years (15.54, 95\% CI: 14.6-16.5) (Mathuranath et al., 2012). In those aged $\geq 65$ years, the world age standardized incidence rate was 21.61 per 100,000 , and standardized against the age distribution for the year 2000 U.S. Census, the age-adjusted incidence rate was 9.19 (95\% CI: 9.03-9.35) per 1000 person-years. Incidence rate of $\mathrm{AD}$ increased significantly and proportionately with increasing age (Mathuranath et al., 2012).

\section{CONCLUSION}

Alzheimer's Disease, being an incurable, degenerative disease requires special care of patients. Various factors like lifestyle, diet, genetic predisposition are thought to cause the disease. Palliative treatment, social awareness and early diagnosis are important. Trained care-giving is an essential part of the disease.

\section{REFRENCES}

1. Capurso, C., Solfrizzi, V., D’Introno, A., Colacicco, A.M., Capurso, S.A., Semeraro, C., Capurso, A., \& Panza, F. (2004). Interleukin 6-174 G/C promoter gene polymorphism and sporadic Alzheimer's disease: geographic allele and genotype variations in Europe. Exp Gerontol., 39(10): 1567- 1573.

2. Chandra, V., Pandav, R., Dodge, H.H., Johnston, J.M., Belle, S.H., \& DeKosky, S.T. (2001). Incidence of Alzheimer's disease in a rural community in India: The Indo-US study. Neurology, 57:985-9.

3. Chen, R., Hu, Z., Wei, L., Ma, Y., Liu, Z., \& Copeland, J. R. (2011). Incident dementia in a defined older Chinese population. PloS one, 6(9), e24817.

4. Chiu, H. F. K., Lam, L. C. W., Chi, I., Leung, T., Li, S. W., Law, W. T., ... \& Lau, J. (1998). Prevalence of dementia in Chinese elderly in Hong Kong. Neurology, 50(4), 1002-1009.

5. Silva, H. D., Gunatilake, S. B., \& Smith, A. D. (2003). Prevalence of dementia in a semi- urban population in Sri Lanka: report from a regional survey. International Journal of Geriatric Psychiatry, 18(8), 711-715.

6. Hou, Y., Dan, X., Babbar, M., Wei, Y., Hasselbalch, S. G., Croteau, D. L., \& Bohr, V. A. (2019). Ageing as a risk factor for neurodegenerative disease. Nature Reviews Neurology, 15(10), 565-581.

7. Jitapunkul, S., Kunanusont, C., Phoolcharoen, W., \& Suriyawongpaisal, P. (2001). Prevalence estimation of dementia among Thai elderly: a national survey. Journal of the Medical Association of Thailand $=$ Chotmaihet thangphaet, 84(4), 461-467.

8. Kalaria, R. N., Maestre, G. E., Arizaga, R., Friedland, R. P., Galasko, D., Hall, K., ... \& World Federation of Neurology Dementia Research Group. (2008). Alzheimer's disease and vascular dementia in developing countries: prevalence, management, and risk factors. The Lancet Neurology, 7(9), 812-826.

9. Liu, C. K., Lai, C. L., Tai, C. T., Lin, R. T., Yen, Y. Y., \& Howng, S. L. (1998). Incidence and subtypes of dementia in southern Taiwan Impact of sociodemographic factors. Neurology, 50(6), 1572-1579.

10. Mansoori, N., Tripathi, M., Alam, R., Luthra, K., Ramakrishnan, L., Parveen, S., \& Mukhopadhyay, A. K. (2010). IL-6-174 G/C and ApoE gene polymorphisms in Alzheimer's and vascular dementia patients attending the cognitive disorder clinic of the all India Institute of Medical Sciences, New Delhi. Dementia and geriatric cognitive disorders, 30(6), 461-468.

11. Mathuranath, P. S., George, A., Ranjith, N., Justus, S., Kumar, M. S., Menon, R., \& Verghese, J. (2012). Incidence of Alzheimer's disease in India: A 10 yearsfollow-up study. Neurology India, 60(6), 625.

12. Wegmann, S., Bennett, R. E., Delorme, L., Robbins, A. B., Hu, M., MacKenzie, D., \& Hyman, B. T. (2019). Experimental evidence for the age dependence of tau protein spread in the brain. Science advances, 5(6), eaaw6404.

13. World Health Organization. (1998). Quality control methods for medicinal plant materials. World Health Organization.

14. Yoshitake, T., Kiyohara, Y., Kato, I., Ohmura, T., Iwamoto, H., Nakayama, K., \& Fujishima, M. (1995). Incidence and risk factors of vascular dementia and Alzheimer's disease in a defined elderly Japanese population: the Hisayama Study. Neurology, 45(6), 1161-1168. 